\title{
Progression of diabetic retinopathy after cataract extraction with intraocular lens implantation
}

\author{
S. Vijayan ${ }^{1}$, Manoj Vasudevan ${ }^{2, *}$ \\ ${ }^{1}$ Senior Resident, Dept. of Ophthalmology, Government Medical College, Sivagangai, Tamil Nadu, ${ }^{2}$ Director and Consultant Eye \\ Surgeon, Janu's Eye Clinic, Chennai, Tamil Nadu, India \\ *Corresponding Author: \\ Email: manojvasudevanms@gmail.com
}

\begin{abstract}
Aim of the study is to observe the progression of diabetic retinopathy in patients after cataract extraction and placement of intraocular lens implantation. Diabetes affects both the anterior as well as the posterior segment of the eyes. In this study we observed the progression of the diabetic retinopathy following uncomplicated cataract surgery with intraocular lens implantation over a one year period and found that the maximum progression was seen at the end of 1 year in patients of age group 56-65 with no gender predilection. Cataract surgery in diabetic patients can be performed with an acceptable risk of complications and worsening of diabetic retinopathy seems to be correlated not with the cataract surgery but with the natural course of diabetic vascular disease.
\end{abstract}

Keywords: Cataract, Diabetic retinopathy, Intraocular lens implantation, Maculopathy, Progression.

\section{Introduction}

Diabetes mellitus (DM) is a systemic disorder of carbohydrate metabolism in which the main finding is chronic hyperglycaemia. The cause is due to either impaired insulin secretion or impaired insulin action or both. Uncontrolled DM affects many organs and one of the most important one to be affected are the eyes which can lead to blindness due to diabetic retinopathy (DR) and maculopathy. It also leads to true diabetic cortical cataract called as the snow flake cataract.

\section{Diagnostic Criteria ${ }^{1}$}

1. $\mathrm{HbAlc} \geq 6.5 \%(\geq 48 \mathrm{mmol} / \mathrm{mol})$

2. Random plasma glucose $\geq 200 \mathrm{mg} / \mathrm{dl}$ $(\geq 11.1 \mathrm{mmol} / \mathrm{l})$

3. Fasting plasma glucose $\geq 126 \mathrm{mg} / \mathrm{dl}(\geq 7.0 \mathrm{mmol} / \mathrm{dl})$

4. OGTT 2-hour glucose in venous plasma $\geq 200 \mathrm{mg} / \mathrm{dl}(\geq 11.1 \mathrm{mmol} / \mathrm{l})$

The eye is one of the most important target organ affected by DM and it causes various complications leading to significant vision loss and blindness. Among these, cataract and diabetic retinopathy (DR) is the most common manifestation and important cause of preventable and avoidable blindness in patients aged between 50-65 years. It is estimated that around 72 million of the global adult population (around 8.2\%) has diabetes and about one-fifth of all adults with diabetes lives in the South-East Asia. In India, around 65 million people have diabetes. ${ }^{2}$ It is estimated that 65 million (17\%) of 382 million persons with diabetes mellitus (DM) globally reside in India. While globally $35 \%$ persons with DM have diabetic retinopathy. ${ }^{3}$

\section{Materials and Methods}

A total of 90 patients with significant cataracts with or without diabetic retinopathy were included in the study. All these patients underwent cataract surgery in one eye and the operated eye was considered as study eye and the fellow eye as the control eye. All the patient's thorough history and clinical examination were done to assess the presence of DR and the staging were done and grouped in the study with informed consent from all patients and enrolled for the study. This prospective case control study was conducted at Aravind eye hospital, Tirunelveli between August 2004 and September 2006 and was approved by the institutional ethics committee and review board.

Both the eyes were followed up at 1 month, 3 months, 6 months and 12 months after the surgery. At every visit best corrected visual acuity (BCVA) with refraction, Intraocular pressure (IOP) and dilated fundus evaluation was done. The assessment and classification of DR was done using the modified Early Treatment Diabetic Retinopathy Study (ETDRS) guidelines. ${ }^{4}$

Inclusion Criteria: All patients with type 1 or 2 Diabetes mellitus (DM) with or without diabetic retinopathy (DR) and cataract in one or both eyes who underwent a complicated or an uncomplicated cataract surgery with artificial intraocular lens implantation (IOL).

Exclusion Criteria: Patients with other systemic diseases which also affect the retina like hypertension, dyslipidema, nephropathy and those patients with retinal pathologies like hereditary retinal dystrophies, macular dystrophies, age related macular degeneration. Patients with co-existent glaucoma, uveitis, prior ocular trauma or any previous intraocular surgeries were also excluded.

All the patients in the study after the history taking regarding the duration and treatment of DM were subjected to standard ocular examination consisting of best corrected visual acuity for distance and near, slit 
lamp biomicroscopy, intra ocular pressure (IOP) measurement and dilated fundus evaluation with classification of the presence of DR and maculopathy according to the ETDRS classification and grouped for the study and underwent cataract surgery with IOL implantation in one eye which became the case eye and the fellow eye became the control eye. These patients were followed for a period of 12 months after the surgery at end of 1 month, 3 months, 6 months and 12 months of their post operative period. Fundus fluorscein angiography (FFA) and optical coherence tomography (OCT) were done whenever indicated for the further management of DR in the follow up period and laser photocoagulation were done in patients requiring them. In patients with poor vision and vision loss not corresponding to the amount of lens opacity were evaluated with OCT-macula to rule out any macular pathology prior to surgery and the macular thickness were documented.

Pearson Chi square test was used to analyze the distribution of age, gender and laterality versus progression of DR in the control and case group. MannWhitney $\mathrm{U}$ test was used to analyze the duration of DM versus progression in the control and case group. Fisher's exact test was used to analyze the presence of Clinically Significant Macular Edema (CSME) in both the groups and a P-value of less than 0.05 was considered to be of statistical significance.

\section{Results and Discussion}

A total of 90 patients were enrolled in the study and followed up for a period of 12 months. Maximum progression of diabetic retinopathy was seen at the end of 12 months of follow up in both the groups among patients in the age group of 56-65 years which was $48.9 \%$ and $47.1 \%$ respectively. We did not find any statistically significant difference among the gender even though there was a slight male predominance as well as between the right eye and the left eye. The duration of the presence of diabetes significantly affected the post operative progression of DR. The eyes which underwent cataract surgery with IOL implantation showed more progression of DR as compared to the non operated eyes and were statistically significant. More number of patients progressed to proliferative DR from severe NPDR or from moderate NPDR in operated eyes as compared to non operated eyes and were statistically significant. There was also statistically significant progression with respect to clinically significant macular edema (CSME) among the operated eyes while none had CSME in the non operated eyes. We found that more the preoperative baseline DR more the progression of DR in the post-operative period after cataract surgery with IOL implantation over an observed period of 12 months in this study. Diabetic patients have an increased risk of cataract development and Cataract extraction(CE) in diabetic patients as compared to non-diabetic patients is associated with higher risks of complications such as capsular contraction and early posterior capsule opacification as well as post-surgical worsening of macular edema (ME) and DR. ${ }^{5}$

In this paper, we analyzed the DR progression following cataract surgery and found that eyes which underwent cataract surgery showed more progression of DR when compared to non operated eyes and even though significant statistically cannot be taken as a contraindication for cataract surgery as the cataract itself will preclude the treating physician/ophthalmologist to look at the fundus for screeing and staging of DR for follow up of these patients. Cataract surgery in diabetic patients can be performed with an acceptable risk of complications and worsening of diabetic retinopathy seems to be correlated not with the cataract surgery but with the natural course of diabetic vascular disease was the conclusion in a study done by Wagner et $\mathrm{al}^{6}$ and in another study done by Ostri et al they concluded that the cataract surgery improved the final visual outcome in patients with DR and cataract regardless of the degree of DR and the apparent progression of DR reflect the masking of low grades of diabetic retinopathy by preoperative lens opacities. ${ }^{7}$ Progression of DR and development of rubeotic glaucoma was reported by Sadiq et al following cataract surgery in DM and DR patients. ${ }^{8}$ A similar study involving 50 patients was studied by Krepler et al in 2002 which concluded that cataract surgery have no influence on the progression of diabetic retinopathy and visual improvement was achieved in the majority of patients with NPDR, but poorer visual outcome was observed in patients developing macular edema following the cataract surgery. ${ }^{9}$ This study did not take into consideration and compare the different types of intraocular lens used in these patients who underwent cataract surgery but compared the type of surgery (Phacoemulsification versus small incision sutureless cataract surgery) with the progression of DR (Table 5 and 6).

Table 1: (Age vs DR status in operated and non operated eyes)

A. Age vs DR status for operated eyes-(p-0.029) pearson chi-square test

\begin{tabular}{|c|c|c|c|c|}
\hline \multirow{2}{*}{ Age } & \multirow{2}{*}{ details } & \multicolumn{2}{|c|}{ DR Status-final } & \multirow{2}{*}{ Total } \\
\cline { 3 - 4 } & & No change & Progression & \\
\hline$<45$ & count & 2 & & 2 \\
\cline { 2 - 3 } & \% within age & $100 \%$ & & $100 \%$ \\
\cline { 2 - 3 } & \% within DR status-final & $4.4 \%$ & & $2.2 \%$ \\
\hline
\end{tabular}




\begin{tabular}{|c|c|c|c|c|}
\hline \multirow{3}{*}{$45-55$} & count & 2 & 11 & 13 \\
\cline { 2 - 5 } & \% within age & $15.4 \%$ & $84.6 \%$ & $100 \%$ \\
\cline { 2 - 5 } & $\%$ within DR status-final & $4.4 \%$ & $24.4 \%$ & $14.4 \%$ \\
\hline \multirow{3}{*}{$55-65$} & count & 28 & 22 & 50 \\
\cline { 2 - 5 } & $\%$ within age & $56 \%$ & $44 \%$ & $100 \%$ \\
\cline { 2 - 5 } & $\%$ within DR status-final & $62.2 \%$ & $48.9 \%$ & $55.6 \%$ \\
\hline $65-75$ & count & 13 & 12 & 25 \\
\cline { 2 - 5 } & \% within age & $52 \%$ & $48 \%$ & $100 \%$ \\
\cline { 2 - 5 } & \% within DR status-final & $28.9 \%$ & $26.7 \%$ & $27.8 \%$ \\
\hline \multirow{3}{*}{ Total } & count & 45 & 45 & 90 \\
\cline { 2 - 5 } & \% within age & $50 \%$ & $50 \%$ & $100 \%$ \\
\cline { 2 - 5 } & $\%$ within DR status-final & $100 \%$ & $100 \%$ & $100 \%$ \\
\hline
\end{tabular}

\begin{tabular}{|c|c|c|c|c|}
\hline \multicolumn{5}{|c|}{ B. Age vs DR status for unoperated eyes-(p-0.582) pearson chi-square test } \\
\hline \multirow[t]{2}{*}{ AGE } & \multirow[t]{2}{*}{ Details } & \multicolumn{2}{|c|}{ DR status-final } & \multirow[t]{2}{*}{ Total } \\
\hline & & No change & Progression & \\
\hline \multirow[t]{3}{*}{$<45$} & Count & 2 & & 2 \\
\hline & $\%$ within age & $100 \%$ & & $100 \%$ \\
\hline & $\%$ within DR status-final & $2.7 \%$ & & $2.2 \%$ \\
\hline \multirow[t]{3}{*}{$45-55$} & count & 9 & 4 & 13 \\
\hline & $\%$ within age & $69.2 \%$ & $30.8 \%$ & $100 \%$ \\
\hline & $\%$ within DR status-final & $12.3 \%$ & $23.5 \%$ & $14.4 \%$ \\
\hline \multirow[t]{3}{*}{$55-65$} & count & 42 & 8 & 50 \\
\hline & $\%$ Within age & $84 \%$ & $16 \%$ & $100 \%$ \\
\hline & \% Within DR status-final & $57.5 \%$ & $47.1 \%$ & $55.6 \%$ \\
\hline \multirow[t]{3}{*}{$65-75$} & count & 20 & 5 & 25 \\
\hline & $\%$ within age & $80 \%$ & $20 \%$ & $100 \%$ \\
\hline & \% Within DR status-final & $27.4 \%$ & $29.4 \%$ & $27.8 \%$ \\
\hline \multirow[t]{3}{*}{ Total } & count & 73 & 17 & 90 \\
\hline & $\%$ within age & $81.1 \%$ & $18.9 \%$ & $100 \%$ \\
\hline & $\%$ Within DR status-final & $100 \%$ & $100 \%$ & $100 \%$ \\
\hline
\end{tabular}

Table 2: (DR status Vs Gender in operated and non operated eyes)

\begin{tabular}{|c|c|c|c|c|}
\hline \multicolumn{5}{|c|}{ A. DR status vs gender for operated eyes-(p-0.667) pearson chi-square test } \\
\hline \multicolumn{2}{|c|}{ Gender } & \multicolumn{2}{|c|}{ DR status-final } & \multirow[t]{2}{*}{ Total } \\
\hline & & No change & Progression & \\
\hline \multirow[t]{3}{*}{ Male } & Count & 26 & 28 & 54 \\
\hline & $\%$ Within gender & $48.1 \%$ & $51.9 \%$ & $100 \%$ \\
\hline & $\%$ Within DR status-final & $57.8 \%$ & $62.2 \%$ & $60 \%$ \\
\hline \multirow[t]{3}{*}{ Female } & Count & 19 & 17 & 36 \\
\hline & $\%$ Within gender & $52.8 \%$ & $47.2 \%$ & $100 \%$ \\
\hline & \% Within DR status-final & $42.2 \%$ & $37.8 \%$ & $40 \%$ \\
\hline \multirow[t]{3}{*}{ Total } & Count & 45 & 45 & 90 \\
\hline & $\%$ Within gender & $50 \%$ & $50 \%$ & $100 \%$ \\
\hline & $\%$ Within DR status-final & $100 \%$ & $100 \%$ & $100 \%$ \\
\hline
\end{tabular}

\begin{tabular}{|l|c|c|c|c|}
\hline \multicolumn{4}{|l|}{ B. DR status vs gender for unoperated eyes-(p-0.995) pearson chi-square test } \\
\hline \multirow{2}{*}{ Gender } & \multicolumn{2}{|c|}{ DR status-final } & \multirow{2}{*}{ Total } \\
\cline { 3 - 4 } & & No change & Progression & \\
\hline \multirow{3}{*}{ Male } & count & 43 & 10 & 53 \\
\cline { 2 - 5 } & $\%$ within gender & $81.1 \%$ & $18.9 \%$ & $100 \%$ \\
\cline { 2 - 5 } & $\%$ within DR status-final & $58.9 \%$ & $58.8 \%$ & $58.9 \%$ \\
\hline \multirow{3}{*}{ Female } & count & 30 & 7 & 37 \\
\cline { 2 - 5 } & $\%$ within gender & $81.1 \%$ & $18.9 \%$ & $100 \%$ \\
\cline { 2 - 4 } & $\%$ within DR status-final & $41.1 \%$ & $41.2 \%$ & $41.1 \%$ \\
\hline
\end{tabular}




\begin{tabular}{|l|c|c|c|c|}
\hline \multirow{3}{*}{ Total } & count & 73 & 17 & 90 \\
\cline { 2 - 5 } & \% within gender & $81.1 \%$ & $18.9 \%$ & $100 \%$ \\
\cline { 2 - 5 } & \% within DR status-final & $100 \%$ & $100 \%$ & $100 \%$ \\
\hline
\end{tabular}

Table 3: (DR status Vs Laterality in operated and non operated eyes)

\begin{tabular}{|l|l|c|c|c|}
\hline \multicolumn{2}{|l|}{ A. DR status vs laterality for operated eyes-(p-0.670) pearson chi-square test } \\
\hline \multirow{2}{*}{ Eye } & \multicolumn{2}{|c|}{ DR Status-Final } & \multirow{2}{*}{ Total } \\
\cline { 3 - 4 } & & No change & Progression & \\
\hline \multirow{3}{*}{ Right } & Count & 27 & 25 & 52 \\
\cline { 2 - 5 } & $\%$ Within eye & $51.9 \%$ & $48.1 \%$ & $100 \%$ \\
\cline { 2 - 5 } & $\%$ Within DR status-final & $60 \%$ & $55.6 \%$ & $57.8 \%$ \\
\hline \multirow{3}{*}{ Left } & Count & 18 & 20 & 38 \\
\cline { 2 - 5 } & $\%$ Within gender & $47.4 \%$ & $52.6 \%$ & $100 \%$ \\
\cline { 2 - 5 } & $\%$ Within DR status-final & $40 \%$ & $44.4 \%$ & $42.2 \%$ \\
\hline \multirow{3}{*}{ Total } & Count & 45 & 45 & 90 \\
\cline { 2 - 5 } & $\%$ Within eye & $50 \%$ & $50 \%$ & $100 \%$ \\
\cline { 2 - 5 } & $\%$ Within DR status-final & $100 \%$ & $100 \%$ & $100 \%$ \\
\hline
\end{tabular}

\begin{tabular}{|c|c|c|c|c|}
\hline \multicolumn{5}{|c|}{ B. DR status vs laterality for unoperated eyes-(p-0.346) pearson chi-square test } \\
\hline \multirow{2}{*}{\multicolumn{2}{|c|}{ Eye }} & \multicolumn{2}{|c|}{ DR Status-Final } & \multirow{3}{*}{$\begin{array}{c}\text { Total } \\
41\end{array}$} \\
\hline & & No change & Progression & \\
\hline \multirow[t]{3}{*}{ Right } & Count & 35 & 6 & \\
\hline & $\%$ Within eye & $85.4 \%$ & $14.6 \%$ & $100 \%$ \\
\hline & $\%$ Within DR status-final & $47.9 \%$ & $35.3 \%$ & $45.6 \%$ \\
\hline \multirow[t]{3}{*}{ Left } & Count & 38 & 11 & 49 \\
\hline & $\%$ Within gender & $77.6 \%$ & $22.4 \%$ & $100 \%$ \\
\hline & $\%$ Within DR status-final & $52.1 \%$ & $64.7 \%$ & $54.4 \%$ \\
\hline \multirow[t]{3}{*}{ Total } & Count & 73 & 17 & 90 \\
\hline & $\%$ Within eye & $81.1 \%$ & $18.9 \%$ & $100 \%$ \\
\hline & \% Within DR status-final & $100 \%$ & $100 \%$ & $100 \%$ \\
\hline
\end{tabular}

Table 4: DR status vs duration of DM in operated and non operated eyes

A. DR status vs duration of DM for operated eyes-(P<0.01) Mann Whitney U test

\begin{tabular}{|l|c|c|c|c|c|c|}
\hline DR Status-Final & N & Range & Minimum & Maximum & Mean & Std. Deviation \\
\hline No Change Duration (in months) & 34 & 168 & 12 & 180 & 52.06 & 47.925 \\
\hline Progression Duration (in months) & 41 & 294 & 6 & 300 & 124.76 & 66.337 \\
\hline
\end{tabular}

\begin{tabular}{|l|c|c|c|c|c|c|}
\hline A. DR status vs duration of DM for operated eyes-(P-0.015) Mann Whitney U test \\
\hline DR Status-Final & $\mathbf{N}$ & Range & Minimum & Maximum & Mean & Std. Deviation \\
\hline No Change Duration (in months) & 60 & 294 & 6 & 300 & 84.75 & 68.032 \\
\hline Progression Duration (in months) & 15 & 216 & 24 & 240 & 128 & 63.606 \\
\hline
\end{tabular}

Table 5: (DR status vs Surgery type in operated eyes)

\begin{tabular}{|c|c|c|c|c|}
\hline \multicolumn{5}{|c|}{ DR Status vs surgery type for operated eyes-(p-0.197) pearson chi-square test } \\
\hline \multirow{2}{*}{\multicolumn{2}{|c|}{ Surgery Type }} & \multicolumn{2}{|c|}{ DR status-final } & \multirow{3}{*}{\begin{tabular}{|c|} 
Total \\
54 \\
\end{tabular}} \\
\hline & & No change & Progression & \\
\hline \multirow[t]{3}{*}{ PHACO } & Count & 24 & 30 & \\
\hline & $\%$ within surgery type & $44.4 \%$ & $55.6 \%$ & $100 \%$ \\
\hline & $\%$ within DR status-final & $53.3 \%$ & $66.7 \%$ & $60 \%$ \\
\hline \multirow[t]{3}{*}{ SICS } & count & 21 & 15 & 36 \\
\hline & $\%$ within surgery type & $58.3 \%$ & $41.7 \%$ & $100 \%$ \\
\hline & $\%$ within DR status-final & $46.7 \%$ & $33.3 \%$ & $40 \%$ \\
\hline \multirow[t]{3}{*}{ Total } & count & 45 & 45 & 90 \\
\hline & $\%$ within surgery type & $50 \%$ & $50 \%$ & $100 \%$ \\
\hline & $\%$ within DR status-final & $100 \%$ & $100 \%$ & $100 \%$ \\
\hline
\end{tabular}


Table 6: (Course of DR vs surgery type)

\begin{tabular}{|c|c|c|c|c|}
\hline \multicolumn{5}{|c|}{ Course of DR vs surgery type-(P-0.769) pearson chi-square test } \\
\hline \multirow[t]{2}{*}{ Course of DR } & \multirow[t]{2}{*}{ Details } & \multicolumn{2}{|c|}{ Surgery type } & \multirow[t]{2}{*}{ Total } \\
\hline & & PHACO & SICS & \\
\hline \multirow[t]{3}{*}{ No DR to NPDR } & Count & 13 & 8 & 21 \\
\hline & $\%$ Within course of DR & $61.9 \%$ & $38.1 \%$ & $100 \%$ \\
\hline & $\%$ Within surgery type & $43.3 \%$ & $53.3 \%$ & $46.7 \%$ \\
\hline \multirow{3}{*}{$\begin{array}{l}\text { Aggravation of } \\
\text { DR }\end{array}$} & Count & 11 & 7 & 18 \\
\hline & $\%$ Within course of DR & $63.6 \%$ & $36.4 \%$ & $100 \%$ \\
\hline & $\%$ Within surgery type & $23.3 \%$ & $26.7 \%$ & $24.4 \%$ \\
\hline \multirow[t]{3}{*}{ No DR to PDR } & Count & 1 & 0 & 1 \\
\hline & $\%$ Within course of DR & $100 \%$ & $0 \%$ & $100 \%$ \\
\hline & $\%$ Within surgery type & $3.3 \%$ & $0 \%$ & $2.2 \%$ \\
\hline \multirow[t]{3}{*}{ NPDR to PDR } & Count & 9 & 3 & 12 \\
\hline & $\%$ Within course of DR & $75 \%$ & $25 \%$ & $100 \%$ \\
\hline & $\%$ Within surgery type & $30 \%$ & $20 \%$ & $26.7 \%$ \\
\hline \multirow[t]{3}{*}{ Total } & Count & 30 & 15 & 45 \\
\hline & $\%$ Within course of DR & $66.7 \%$ & $33.3 \%$ & $100 \%$ \\
\hline & $\%$ Within surgery type & $100 \%$ & $100 \%$ & $100 \%$ \\
\hline
\end{tabular}

Table 7: (Course of DR vs group)

\begin{tabular}{|l|c|c|c|c|}
\hline roup vs course of DR-(p-0.091) pearson chi-square test \\
\hline \multirow{2}{*}{ Course of DR } & Details & \multicolumn{2}{|c|}{ Group } & \multirow{2}{*}{ Total } \\
\cline { 2 - 5 } & & Cases & Control & \\
\hline \multirow{2}{*}{$\begin{array}{l}\text { No DR to } \\
\text { NPDR }\end{array}$} & Count & 21 & 10 & 31 \\
\cline { 2 - 5 } & $\%$ Within course of DR & $67.7 \%$ & $32.3 \%$ & $100 \%$ \\
\cline { 2 - 5 } & $\%$ Within group & $46.7 \%$ & $58.8 \%$ & $50 \%$ \\
\hline \multirow{3}{*}{$\begin{array}{l}\text { Aggravation of } \\
\text { No DR to PDR }\end{array}$} & Count & 11 & 7 & 18 \\
\cline { 2 - 5 } & $\%$ Within course of DR & $61.1 \%$ & $38.9 \%$ & $100 \%$ \\
\cline { 2 - 5 } & $\%$ Within group & $24.4 \%$ & $41.2 \%$ & $29 \%$ \\
\cline { 2 - 5 } & Count & 1 & 0 & 1 \\
\cline { 2 - 5 } & $\%$ Within course of DR & $100 \%$ & $0 \%$ & $100 \%$ \\
\hline \multirow{3}{*}{ NPDR to PDR } & Count & $2.2 \%$ & $0 \%$ & $1.6 \%$ \\
\cline { 2 - 5 } & $\%$ Within course of DR & 12 & 0 & 12 \\
\cline { 2 - 5 } & $\%$ Within group & $26.7 \%$ & $0 \%$ & $100 \%$ \\
\hline \multirow{3}{*}{ Total } & Count & 45 & 17 & 62 \\
\cline { 2 - 5 } & $\%$ Within course of DR & $72.6 \%$ & $27.4 \%$ & $100 \%$ \\
\cline { 2 - 5 } & $\%$ Within group & $100 \%$ & $100 \%$ & $100 \%$ \\
\hline
\end{tabular}

Table 8 (Group vs clinically significant macular edema-CSME in cases and control eyes)

\begin{tabular}{|c|c|c|c|c|}
\hline \multicolumn{5}{|c|}{ Group vs CSME-(P-0.014) Fisher's exact test } \\
\hline \multicolumn{2}{|c|}{ Presence of CSME } & \multicolumn{2}{|c|}{ Group } & \multirow{3}{*}{\begin{tabular}{|c|} 
Total \\
173 \\
\end{tabular}} \\
\hline & & \multirow{2}{*}{$\begin{array}{c}\text { Cases } \\
83\end{array}$} & \multirow{2}{*}{$\begin{array}{c}\text { Control } \\
90\end{array}$} & \\
\hline CSME-Absent & Count & & & \\
\hline & \% Within CSME & $48 \%$ & $52 \%$ & $100 \%$ \\
\hline & $\%$ Within group & $92.2 \%$ & $100 \%$ & $96.1 \%$ \\
\hline \multirow[t]{3}{*}{ CSME -present } & Count & 7 & 0 & 7 \\
\hline & \% Within CSME & $100 \%$ & $0 \%$ & $100 \%$ \\
\hline & $\%$ Within group & $7.8 \%$ & $0 \%$ & $3.9 \%$ \\
\hline \multirow[t]{3}{*}{ Total } & Count & 90 & 90 & 180 \\
\hline & \% Within CSME & $50 \%$ & $50 \%$ & $100 \%$ \\
\hline & $\%$ Within group & $100 \%$ & $100 \%$ & $100 \%$ \\
\hline
\end{tabular}


Table 9: (DR status vs cystoid macular edema-CME in operated eyes)

\begin{tabular}{|l|c|c|c|c|}
\hline \multicolumn{3}{|c|}{ DR Status vs CME for operated eyes-(p-0.157) fisher's exact test } \\
\cline { 3 - 4 } \multicolumn{2}{|c|}{ Presence of CSME } & \multicolumn{2}{c|}{ Group } & \multirow{2}{*}{ Total } \\
\hline \multirow{3}{*}{ CME-Absent } & Count & 43 & 38 & 81 \\
\cline { 2 - 4 } & $\%$ Within CME & $53.1 \%$ & $46.9 \%$ & $100 \%$ \\
\cline { 2 - 4 } & $\%$ Within DR status & $95.6 \%$ & $84.4 \%$ & $90 \%$ \\
\hline \multirow{3}{*}{ CME-Present } & Count & 2 & 7 & 9 \\
\cline { 2 - 4 } & $\%$ Within CME & $22.2 \%$ & $77.8 \%$ & $100 \%$ \\
\cline { 2 - 4 } & $\%$ Within DR status & $4.4 \%$ & $15.6 \%$ & $10 \%$ \\
\hline \multirow{3}{*}{ Total } & Count & 45 & 45 & 90 \\
\cline { 2 - 5 } & $\%$ Within CME & $50 \%$ & $50 \%$ & $100 \%$ \\
\cline { 2 - 5 } & $\%$ Within DR status & $100 \%$ & $100 \%$ & $100 \%$ \\
\hline
\end{tabular}

\section{Conclusion}

Presence of DR is not a contraindication for cataract surgery with IOL implantation however those patients DR should be closely monitored in the post operative period for early signs of progression and whenever necessary laser photocoagulation should be done to avoid blindness. The most important factor in the progression of DR and development of maculopathy is the age and the duration of the diabetes. In cases of suspicious posterior segment in patients with DM and cataract, prior to undergoing cataract surgery, nowadays an optical coherence tomography (OCT) can be documented for analyzing the progression of maculopathy in these patients in the follow up period and treated early to prevent vision loss. ${ }^{10,11}$ This study found there is significant progression of DR after cataract surgery irrespective of gender and right or left eye with increase in age and the duration of Diabetes. DM affects both the anterior and posterior segment of the eye, ${ }^{12}$ so it is recommended to keep adequate control of the DM with the physician and a regular yearly dilated fundus or as recommended by the ophthalmologist to prevent/avoid blindness or vision loss due to diabetes.

\section{References}

1. Kerner W, Brückel J. Definition, classification and diagnosis of diabetes mellitus. Exp Clin Endocrinol Diabetes. 2014;122(7):384-6.

2. Raman R, Gella L, Srinivasan S, Sharma T. Diabetic retinopathy: An epidemic at home and around the world. Indian J Ophthalmol. 2016;64(1):69-75.

3. Murthy GV, Das T. Diabetic care initiatives to prevent blindness from diabetic retinopathy in India. Indian J Ophthalmol. 2016;64(1):50-54.

4. Grading diabetic retinopathy from stereoscopic color fundus photographs-an extension of the modified Airlie House classification. ETDRS report number 10. Early
Treatment Diabetic Retinopathy Study Research Group. Ophthalmology. 1991;98(5 Suppl):786-806.

5. Haddad NM, Sun JK, Abujaber S, Schlossman DK, Silva PS. Cataract surgery and its complications in diabetic patients. Semin Ophthalmol. 2014; 29(56):329-337.

6. Wagner T, Knaflic D, Rauber M, Mester U. Influence of cataract surgery on the diabetic eye: a prospective study. Ger J Ophthalmol. 1996;5(2):79-83.

7. Ostri C, Lund-Andersen H, Sander B, La Cour M. Phacoemulsification cataract surgery in a large cohort of diabetes patients: visual acuity outcomes and prognostic factors. J Cataract Refract Surg. 2011;37(11):2006-12.

8. Sadiq SA, Chatterjee A, Vernon SA. Progression of diabetic retinopathy and rubeotic glaucoma following cataract surgery. Eye (Lond). 1995;9(Pt 6):728-738.

9. Krepler K, Biowski R, Schrey S, Jandrasits K, Wedrich A. Cataract surgery in patients with diabetic retinopathy: visual outcome, progression of diabetic retinopathy, and incidence of diabetic macular oedema. Graefes Arch Clin Exp Ophthalmol. 2002;240(9):735-738.

10. Kwon SI, Hwang DJ, Seo JY, Park IW. Evaluation of changes of macular thickness in diabetic retinopathy after cataract surgery. Korean $J$ Ophthalmol. 2011;25(4):238-242.

11. Baker CW, Almukhtar T, Bressler NM, Glassman AR, Grover S, Kim SJ, Murtha TJ, Rauser ME, Stockdale C. Macular edema after cataract surgery in eyes without preoperative central-involved diabeticmacular edema. Diabetic Retinopathy Clinical Research Network. JAMA Ophthalmol. 2013;131(7):870-9.

12. Manoj vasudevan. Eye manifestations of diabetes mellitus. Chettinad Healthcity Medical Journal. 2012;1(4):163-68.

How to cite this article: Vijayan S, Vasudevan M. Progression of diabetic retinopathy after cataract extraction with intraocular lens implantation. Ind $\mathbf{J}$ Clin Exp Ophthalmol. 2018;4(3):352-357. 